GESTÃO PÚBLICA E GOVERNANÇA 


\title{
CONTRATAÇÕES PÚBLICAS SUSTENTÁVEIS: PRÁTICAS E INFLUÊNCIAS NA GESTÃO MUNICIPAL
}

\author{
SUSTAINABLE PUBLIC PROCUREMENT: \\ PRACTICES AND INFLUENCES IN MUNICIPAL MANAGEMENT
}

Bruno Alencar da Costa

Universidade da Amazônia

Mário Vasconcellos Sobrinho

Universidade da Amazônia

Ynis Cristine de Santana Martins Lino Ferreira

Universidade da Amazônia

Data de submissão: 2 l jun. 20 |6. Data de aprovação:

I 8 abr. 2017. Sistema de avaliação: Double blind review.

Universidade FUMEC / FACE. Prof. Dr. Henrique Cordeiro

Sergio Castro Gomes

Martins. Prof. Dr. Cid Gonçalves Filho.

Universidade da Amazônia

\section{RESUMO}

O objetivo deste estudo é a análise dos principais fatores que influenciam a prática das contratações sustentáveis na administração pública em âmbito municipal, tomando como base a visão dos agentes públicos municipais. Trata-se de um estudo exploratório, dada a incipiência da aplicação da regulamentação das contratações sustentáveis em uma esfera administrativa descentralizada. Os dados foram coletados por meio de questionários aplicados para uma amostra não probabilística e selecionada por conveniência, considerando a indisponibilidade do número total população de agentes públicos municipais. Identificou-se os fatores de Sustentabilidade Imanente, Alinhamento Estratégico Sustentável e de Eficácia Legal. Diante disso, a adaptação de um framework específico para a análise e tratamento dos processos de licitações e contratos sustentáveis praticados em uma realidade local foi lograda com algumas ressalvas, referentes às limitações associadas a um estudo amparado em amostra não probabilística.

\section{PALAVRAS-CHAVE}

Contratos Públicos Sustentáveis. Licitações. Administração Pública. Análise de Fatores. Municípios. 


\section{ABSTRACT}

The goal of this study is to analyse the main factors that have influence on the practice of sustainable hiring in the public administration in a municipality scale. The municipal agents perspective while performing this study is analized. Given the seminal state of the application of regulation to sustainable hirings in a decentralized administrative level, an exploratory approach in this study is. Data was collected through questionnaires that were applied to a non-probability sample and selected by convenience, considering the unavailability of the total population of municipal agents. Three factors as the most important were identified: Immanent Sustainability, Sustainable Strategic Alignment and Legal Effectiveness. Therefore, a specificframework to analyse the hiring processes and sustainable contracts that are practiced in a local environment.was adapted. Finally, as any study that is based on a non-probabilistic sample, this work has limitations that are further discussed.

\section{KEYWORDS}

Sustainable Public Procurement. Biddings. Public Administration. Factors Analysis. Municipality.

\section{INTRODUÇÃO}

O interesse sobre o uso sustentável dos recursos naturais em âmbito global, apesar de suas diversas perspectivas e questionamentos, vem se consolidando nos ambientes acadêmicos, institucionais e corporativos. Um desses questionamentos é a indicação de determinado objeto ou ação como sustentável em todo o seu escopo, surgindo a necessidade de estabelecimento de conceitos, parâmetros e variáveis.

Dentre os diversos agentes envolvidos na definição e promoção de políticas sustentáveis, o Estado, além de seu reconhecido papel regulador, também é capaz de agir no espaço não regulatório ao ser um expressivo consumidor em termos de volume (e seus respectivos valores) de produtos Alencastro, Silva e Lopes (2014) que desenha comportamentos para sociedade por via de regras de certames para a sele- ção de seus fornecedores. É diante dessa dinâmica que no Brasil, em particular na gestão pública, pode-se apontar os contratos públicos sustentáveis como um instrumental capaz de ir ao encontro do paradigma da sustentabilidade, para proteção/ preservação dos bens comuns, tendo implicações, nãos somente em todos os níveis governamentais, assim como nos espaços de mercado e sociedade civil.

As compras sustentáveis ou compra verde, instituída pela Lei I $2.349 / 10$ e regulamentada pela Instrução Normativa n. OI do Ministério do Planejamento, Orçamento e Gestão, surgem como ensejo de operacionalização da promoção do desenvolvimento nacional sustentável incorporado às contratações públicas regulamentadas pela Lei 8.666/93. Ambas as normas apresentam em seu escopo diretrizes para orientar os administradores com relação à aplicação 
de critérios sustentáveis aos itens licitados pelo estado (BRASIL, 20I I).

Dada a incipiência - em função da recente implementação do marco legal para contratações públicas sustentáveis - no desenvolvimento de critérios de julgamento e práticas de gestão sustentáveis nos processos de contratação na administração pública, faz-se necessária a definição de um meio consistente de aferição da eficácia, que seja capaz de fornecer um feedback mais abrangente para $\circ$ aperfeiçoamento dos processos de aquisição dos bens e serviços da Administração Pública.

Por outro lado, o marco legal dos contratos públicos sustentáveis advém de uma estrutura centralizada federativa, sendo importante a análise de sua aplicação e compreensão em regiões distintas com realidades e características diversas de sua origem.Assim, surge o desafio de satisfazer os interesses locais da administração em consonância com as políticas de desenvolvimento sustentável de forma abrangente.

Nesse sentido, considerando os municípios brasileiros como unidades administrativas descentralizadas na estrutura da gestão pública nacional, a compreensão das práticas de contratações sustentáveis e sua consolidação no nível municipal, visando o apoio das cadeias de valores e arranjos produtivos de acordo com as especificidades locais, deve ser explorada. Sendo assim, a capilaridade de normas e procedimentos de aquisições sustentáveis em nível municipal demanda a identificação dos elementos que a influenciam.

Nesse contexto, o Estado do Pará, dada as suas peculiaridades e grandes desafios logísticos resultantes de sua vasta extensão territorial de aproximados $1.248 .000 \mathrm{Km} 2$, com sua baixa densidade demográfica $(6,38$ hab./ $\left.\mathrm{km}^{2}\right)$, distribuída em 144 municípios IBGE (2010) além de sua abundância de recursos naturais que reforçam o simbolismo da noção de sustentabilidade; pode ensejar novas perspectivas para consolidação das práticas sustentáveis de contratação, possibilitando avanço das discussões em torno da definição de critérios sustentáveis para contratação de fornecedores.

O objetivo deste estudo é a análise dos principais fatores que influenciam a prática das contratações sustentáveis na administração pública em âmbito municipal, tomando como base a visão dos agentes públicos municipais. Para tanto, realizou-se um levantamento dentre uma amostra não probabilística de agentes públicos de 14 municípios do Estado do Pará, cujos dados obtidos foram processados pelo método de análise fatorial e revelaram a influência de três fatores a saber: Sustentabilidade Imanente, Alinhamento Estratégico Sustentável e Eficácia Legal

Os resultados obtidos propiciam o aprofundamento das discussões sobre os condicionantes internos e externos para que influenciam na realização de compras orientadas por uma política pautada na noção de sustentabilidade, bem como contribui para questão da adequação das normas de licitações existentes quando da sua aplicação em ambientes heterogêneos, podendo subsidiar ações de melhorias futuras em processos de licitações e contratos na administração pública.

Para a melhor apresentação de tal intento, este artigo está dividido em seis sessões contando com esta introdução. A sessão dois discorre sobre a concepção de contratações sustentáveis e seu contexto nacional. $\mathrm{Na}$ sessão três é apresentado o modelo conceitual adotado para nortear 
a aplicação dos materiais é métodos apresentados na sessão quatro. A sessão cinco foi reservada para a discussão dos resultados alcançados que possibilitam as observações contidas nas considerações finais da sexta e última sessão.

\section{CONTRATAÇÕES SUSTENTÁVEIS}

A consolidação da abordagem das atuais políticas de promoção das compras governamentais sustentáveis advém das atividades da Força Tarefa de Marrakesh, realizada no período que inicia em 2006 até maio de 201 I. Seu desenvolvimento é justificado pela tendência ao longo da evolução das discussões, em torno de políticas públicas sustentáveis no âmbito global, em reconhecer o ente governamental, dado do seu significativo volume de aquisições, como agente econômico capaz de incentivar a adoção de práticas sustentáveis pelos demais agentes do mercado (BETIOL; UEHARA; LALOE et al., 20I2).

Desde então, o principal desafio em vista é o de estabelecer uma metodologia padrão para fins de implementação de políticas nacionais de aquisições sustentáveis. Para tanto, foi realizado pelo Programa das Nações Unidas para o Meio Ambiente (PNUMA) um projeto piloto em sete países cujos impactos produzidos foram avaliados para a identificação dos benefícios obtidos com a adoção da abordagem de compras sustentáveis, bem como para a elaboração de indicadores de desempenho capazes de auferir o grau de sustentabilidade obtido por meio das aquisições (UNEP, 20 I2).

Em que pese os avanços no campo institucional, refletidos na elaboração de planos de ações para a implementação de um sistema de compras sustentáveis em diferentes países, e na adoção de diretrizes para análise como o ciclo de vida do produto e o modelo triple bottom line (que abrange os aspectos econômicos, sociais e ambientais), ainda é possível constatar algumas limitações relacionadas ao grau de maturidade dos agentes políticos de cada país, desde a prioridade baixa definida pela vontade política até pouco conhecimento relacionados aos conceitos e processos que envolvem as aquisições sustentáveis (UNEP, 20 I2b).

De acordo com McCrudden (2004), o uso de aquisições públicas como meio de promoção de políticas socialmente inclusivas é uma prática recorrente desde o século XIX em países como Inglaterra, França e Estados Unidos, seja para a consolidação de melhorias nas relações de trabalho, influência de padrões mínimos de remuneração ou para a inserção de grupos socialmente vulneráveis (ex-combatentes inválidos, negros, aborígenes, etc.) como participantes de contratos públicos. Diante disso, a emergência dos estímulos ao desenvolvimento e oferta de produtos e serviços alinhados com o equilíbrio ambiental, recentemente incorporada como política das contratações públicas, imprime a busca por soluções integradoras das dimensões sócias e ambientais que caracterizam as aquisições públicas sustentáveis.

No Brasil, o processo de desenvolvimento das licitações sustentáveis ganhou corpo inicialmente no âmbito subnacional e local (estados de Minas Gerais, São Paulo e cidade de São Paulo), para então ganhar escala na administração federal em 2010, após a publicação da Instrução Normativa No.I, do Ministério do Planejamento, Orçamento e Gestão (MPOG). Em seguida a alteração dada à Lei 8.666 reforçou o processo para a adoção de critérios sustentáveis nas compras públicas. $\bigcirc$ processo 
culminou com a publicação do Decreto $n^{\circ}$. 7.746, de 5 de junho de 20I2, no qual o governo especifica que "a administração pública federal direta, autárquica e fundacional e as empresas estatais dependentes poderão adquirir bens e contratar serviços e obras considerando critérios e práticas de sustentabilidade objetivamente definidos no instrumento convocatório" (BETIOL; UEHARA; LALOE et al. 20I2).

Os processos licitatórios, suas exceções e seus contratos administrativos decorrentes são atualmente regulamentados pela Lei $n^{\circ}$ 8.666/1993, na qual em seu Artigo $3^{\circ}$, identifica como essencialidade da licitação para a Administração Pública, dentre outras, a promoção do desenvolvimento nacional sustentável. À atual redação desse artigo, foram inseridos em época mais recente (mediante a Lei $n^{\circ}$ 12.349/10) os elementos de promoção do desenvolvimento nacional e da sustentabilidade.

Nesse caso, ainda tendo como base a legislação, a promoção do desenvolvimento nacional se traduz na prática da concessão de margens preferenciais na seleção e privilégios na contratação de fornecedores que comprovem seu enquadramento na categoria de microempresas ou empresas de pequeno porte (de acordo com a Lei Complementar 123/2016); produzam bens e serviços nacionais (Decreto $\mathrm{n}^{\circ}$ $7.546 / 20$ II) ou que invistam em pesquisa e desenvolvimento de tecnologia no Brasil, além de priorizar a compra de produtos que utilizem matérias-primas e tecnologias locais (Lei $n^{\circ}$ II.196/2005).

Dessa forma, para garantir que tais empresas sejam sustentáveis, a legislação estabelece como diretrizes de sustentabilidade: o menor impacto de recursos naturais como flora, fauna, solo e água; maior eficiência na utilização de recursos naturais como água e energia; maior vida útil e menor custo de manutenção do bem e da obra; utilização de recursos naturais de origem ambientalmente regular; entre outros. (Decreto $n^{\circ} 7.756 / 2012$ ).

Segundo Nascimento; Zittei; Souza et al. (20।4), em âmbito nacional, numa perspectiva legalista, a utilização dos critérios "verdes" nas contratações públicas implica negativamente no princípio da competitividade entre os licitantes e em alguns casos na eventual quebra de economicidade, pois os produtos que atendem aos critérios sustentáveis apresentam um custo mais elevado.

Não obstante, um desafio que se coloca para a administração pública é o atendimento da proposta mais vantajosa e desenvolvimento sustentável (Lei $\left.n^{\circ} 8.666 / 93\right)$ e a manutenção da competitividade. Em primeiro lugar superar o paradigma de que se deve primar pelo menor preço, adquirindo produtos ou serviços com má qualidade, outrossim, adquirir produtos e serviços capazes de agregar maior benefício para a coletividade, tendo compensando o valor pago através da geração de economia a longo prazo (NASCIMENTO; ZITTEI; SOUZA et al. 2014).

Em segundo lugar, a escolha dos bens e serviços contratados pela administração pública deve priorizar a adoção de critérios sustentáveis, visando atender a supremacia do interesse público sobre o particular (NASCIMENTO; ZITTEI; SOUZA et al. 20|4).

Portanto, mediante as recentes alterações na redação da Lei $8.666 / 93$ a sua importância estratégica na propagação de políticas públicas que visem ao fomento de competitividade e sustentabilidade o mer- 
cado, além da tradicional busca pela melhor utilização dos recursos públicos e da prevenção contra a corrupção; mesmo que se trate de normatizar uma atividade de apoio para o alcance dos objetivos da administração pública.

As compras sustentáveis correspondem a uma pequena parcela de $0,06 \%$ do total das compras públicas federais (BRASIL, 20I4). No exercício financeiro de 2014 verificou-se um decréscimo de $14 \%$ das compras sustentáveis em relação ao ano anterior, acentuando uma tendência contrária à promissora evolução observada no ano de 2012, quando as compras sustentáveis cresceram em 198\% em toda a administração federal. Porém, a tendência de aumento da participação das compras sustentáveis em relação ao volume total de compras na administração federal manteve sua tendência de crescimento, além de apresentar uma significante associação com a participação de microempresas e empresas de pequeno porte (a participação destas no ano de 2014 correspondeu a $66,8 \%$ e $83 \%$ no ano anterior, perante o total dos processos de compras sustentáveis) (BRASIL, 20I4).

Alencastro, Silva e Lopes (2014) refletem acerca da efetividade das compras públicas sustentáveis, considerando duas contratações: a) as licitações sustentáveis se pulverizam no Ministério da Educação e nos órgãos vinculados à estrutura desse ministério nos estados brasileiros, b) apesar do aumento no percentual de aquisições sustentáveis, mais da metade dos órgãos do Poder Executivo federal tem participação inexpressiva nesse processo. Essas constatações demandam uma atuação do MPOG para fiscalizar, identificar e corrigir as causas desse cenário institucional.

\section{O MODELO CONCEITUAL}

Visando a entender o tratamento das questões referentes às principais influências existentes nos processos de aquisições e contratações públicas no âmbito da gestão municipal do Estado do Pará, partimos da estrutura conceitual apresentada por Gelderman, Ghijsen e Brugman (2006) e aperfeiçoada por Brammer e Walker (20II), ao abordarem os principais fatores de influência na aplicação de aquisições sustentáveis na União Europeia e em nível mundial.

Diante da constatação de um significativo não cumprimento das principais diretrizes em vigor acerca das contratações sustentáveis no âmbito da União Europeia, Gelderman, Ghijsen e Brugman (2006) definiram quatro variáveis explanatórias interdependentes e detentoras de relações positivas ou negativas com o nível de cumprimento de regras estabelecidas para aquele local (Figura I).

São quatro variáveis explicativas para esse modelo. A primeira é a familiaridade com as regras, ou seja, o grau de esclarecimento que os agentes públicos possuem quanto suas obrigações e possíveis casos de exceções evitando a tomada de decisão arbitrária e mal interpretada. Segundo os autores, a familiaridade impacta positivamente neste modelo.

A segunda variável é a ineficiência percebida na qual emerge a crítica relacionada à ausência das melhores práticas de aquisição e negociação ao longo das regras estabelecidas, impactando negativamente no modelo (GELDERMAN; GHIJSEN; BRUGMAN, 2006).

Os incentivos organizacionais constituem a terceira variável que influencia positivamente o modelo na medida em que abrange os aspectos motivacionais dos 
agentes públicos que perpassam pelo receio de sofrerem sanções ou voluntarismo, ética e etc. Gelderman, Ghijsen e Brugman (2006). E, a última variável é a resistência dos fornecedores no sentido de pressionar os agentes públicos para cumprimento efetivo das medidas legais estabelecidas no certame e na fase de contrato das aquisições públicas sustentáveis, impactando positivamente o modelo (GELDERMAN; GHIJSEN; BRUGMAN, 2006).

Avançando na discussão sobre as principais influências exercidas nos processos de aquisições sustentáveis por meio de um estudo comparativo envolvendo diversos países no globo, Brammer e Walker (20I I) adaptam o modelo de Gelderman, Ghijsen e Brugman (2006), e inserem o contexto político de cada país sobre as variáveis do modelo, definindo, assim, seus comportamentos positivos ou negativos sobre as contratações sustentáveis (Figura 2).

Custos e benefícios percebidos exercem um papel importante na efetivação da prática de aquisição, pois o (des) alinhamento da questão sustentável com a viabilidade financeira do produto ofertado determi- na o (in) sucesso em relação à política de contratações sustentáveis (BRAMMER e WALKER, 20II). Já a familiaridade com a política sustentável constitui um segundo fator no qual está contido o conhecimento referente ao conceito e normas da sustentabilidade, bem como às competências requeridas para que esta seja efetivada.

terceiro fator de influência se refere à disponibilidade dos produtos sustentáveis entre os fornecedores participantes do certame. $O$ último fator de influência consiste nos incentivos e/ou pressões para a prática de licitações sustentáveis dependendo para isso da cultura organizacional e do grau de envolvimento dos gestores responsáveis por tomada de decisão.

\section{MATERIAIS E MÉTODOS}

A natureza da pesquisa deste trabalho pode ser classificada em parte como exploratória ao adentrar em um campo do qual ainda não se dispõe de informações relevantes de seus elementos, bem como de suas relações Sampieri, Fernández e Baptista Lucio (20।0), sendo o caso da caracterização dos processos de contratações susten-

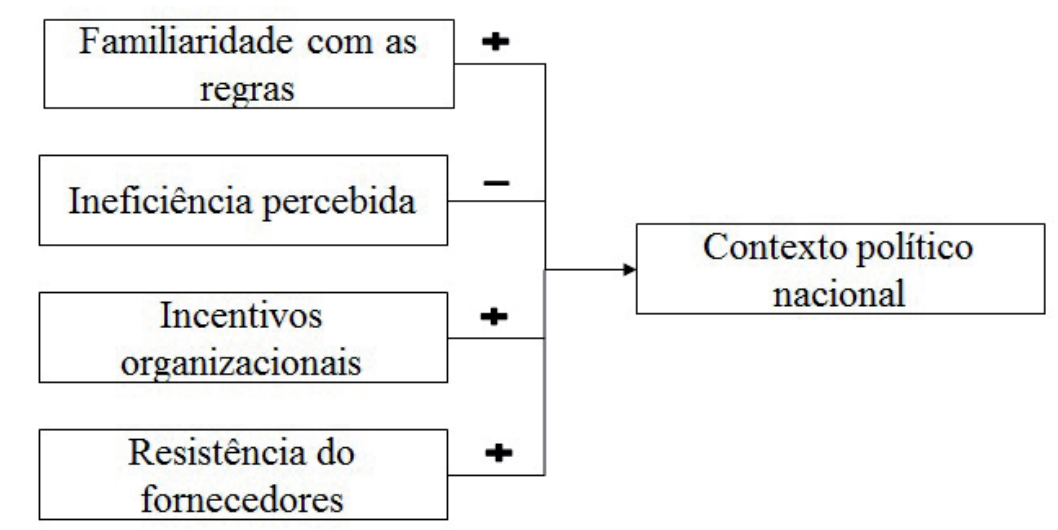

FIGURA 1 - Modelo conceitual para explicação do cumprimento das regras de certames na União Europeia.

Fonte: Gelderman et al. (2006) 


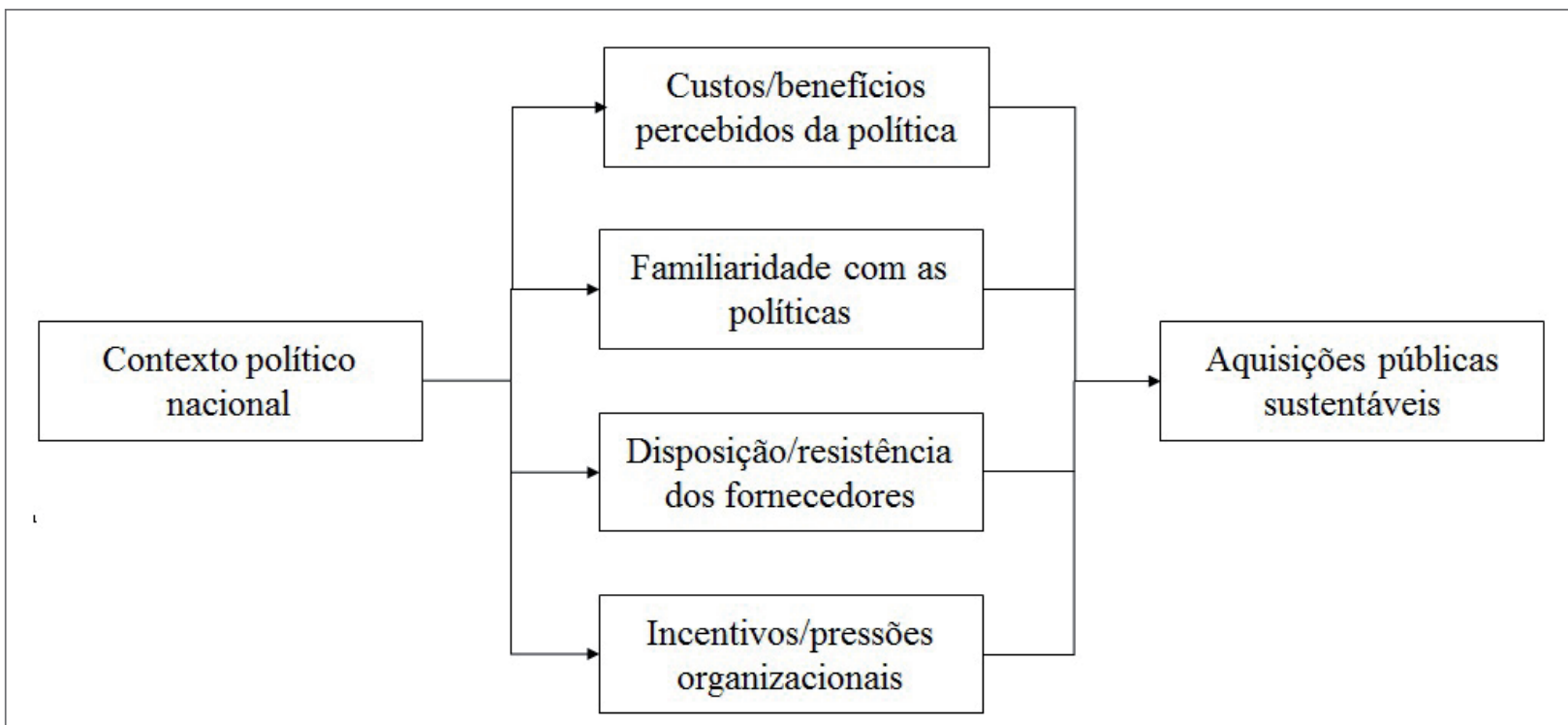

FIGURA 2 - Modelo conceitual de influências sobre contratações sustentáveis

Fonte: Brammer \& Walker (2011)

táveis em âmbito da administração pública municipal inserida no Estado do Pará, dada incipiência da aplicação da regulamentação das contratações sustentáveis em uma esfera administrativa mais descentralizada e periférica. Assim como também descritiva, pois visa identificar as relações estabelecidas entre os elementos do objeto estudado, com como suas características (GIL, 20I0). Ademais, seus resultados estão alicerçados em um modelo conceitual pré-estabelecido, cujos constructos servem de alicerce para a construção do cenário e definição das políticas a serem observadas nas práticas de contratações sustentáveis circunscritas ao local estudado, no caso, o Estado do Pará.

Em relação aos dados utilizados, estes foram construídos por meio de questionários aplicados para uma amostra não probabilística - selecionada por conveniência, considerando a indisponibilidade do número total população de agentes públicos municipais - sendo compostos de um bloco de dez perguntas fechadas: nove destas de escala de avaliação tipo Likert de 5 pontos: I (ine- xistente), 2 (baixo), 3 (médio), 4 (bom) e 5 (excelente) e uma de escolha simples (entre sim e não) com opção para texto de resposta. Dentre os 100 questionários submetidos durante 0 mês de novembro do ano de 2014 , obteve-se 42 questionários respondidos, dos quais foram aproveitados 40 , provenientes de 14 municípios dentre os 144 que constituem o estado, abrangendo quatro das suas seis mesorregiões (não houve municípios representantes mesorregiões do Baixo Amazonas e do Sudoeste Paraense).

\section{Análise Fatorial}

Considerando o escopo conceitual utilizado para análise (Seção 3), bem como a busca pela identificação das principais influências exercidas sob o objeto delimitado (licitações sustentáveis na administração pública municipal no estado do Pará), foi utilizada a análise fatorial, cujo principal objetivo é o de reduzir a redundância de diversas variáveis compactando-as em fatores numericamente reduzidos (RENCHER, 2002). 
A análise fatorial, além de propiciar a consolidação dos dados para melhor análise, também viabiliza um meio para consolidar ou ajustar o alcance teórico na medida em que aufere o grau de interdependência entre variáveis (HAIR; BLACK; BABIN et al. 2009).

\section{Variáveis utilizadas}

O Quadro I demonstra as dez variáveis empregadas para a caracterização dos principais fatores identificados bem como suas respectivas perguntas constantes no questionário aplicado.

\section{RESULTADOS E DISCUSSÃO}

O emprego da análise de componentes para as variáveis elencadas identifica a formação de três componentes principais, responsáveis por aproximadamente $76 \%$ da explicação do total de variâncias insignificantes, conforme o demonstrado por meio da observação dos percentuais de variação dos autovalores de cada componente (Tabela 2), os quais evidenciam a abrupta redução do peso dos autovalores encontrados para os componentes de número 4 em diante.

Também é possível assumir a amostra como válida, uma vez que expressa um razoável grau de correlação entre as variáveis de acordo com o resultado acima de 0,5 obtido para o teste Kaiser-Meyer-Olkin $(0,608)$, refutada a hipótese de que seus dados constituem uma matriz identidade pelo teste de esfericidade de Barlett.

Por meio do algoritmo de rotação Varimax, os três principais componentes, na ordem do que possui a maior carga fatorial para a menor, são dotados das respectivas variâncias em 3I, 25 e 20 por cento, sob as quais foram açambarcadas todas as dez variáveis elencadas para a identificação dos constructos.

Nesse ponto é importante ressaltar a decisão de se manter a variável "Eficácia de Aquisições", em que pese o seu baixo valor de comunalidade $(0,583)$ comparado às demais variáveis com valores acima de 0,6 (Tabela 3). Isso se deve ao considerarmos que o seu comportamento enseja a interpretação de um aspecto bastante relevante para a compreensão da realidade do objeto estudado, dada a sua relação negativa com as demais variáveis constituintes de um mesmo fator que será adiante apresentado.

Assim, tendo em conta as suas variáveis de influência dispostas de acordo com a Matriz de Componentes Rotacionados (Tabela 3) adentramos à análise de cada um dos três componentes para atribuir-lhes as mais adequadas definições.

O primeiro componente de maiores cargas fatoriais é formado por quatro variáveis: Aquisições Sustentáveis, Critérios Sustentáveis, Benefícios Organizacionais e Preparo dos Fornecedores. A junção dessas variáveis denota a conciliação dos princípios norteadores dos processos de contratações sustentáveis com os interesses e objetivos organizacionais da unidade gestora municipal, sendo comum a materialização desses princípios por meio de critérios sustentáveis de avaliação para a seleção de fornecedores de produtos adequados às especificidades das demandas do órgão.

Nesse contexto, o grau de preparo dos fornecedores, também pode constituir um reforço ou sabotagem para a manutenção dos ritos processuais estabelecidos em leis ou normas internas (BETIOL; UEHARA; LALOE et al. 2012 ; GELDERMAN; GHIJSEN; BRUGMAN, 2006). Uma análise da 


\section{QUADRO 1 - Variáveis com suas respectivas perguntas para identificação das principais influências exercidas sob as Licitações Sustentáveis na Administração Pública Municipal no estado do Pará}

\begin{tabular}{|c|c|c|}
\hline VARIÁVEL & DESCRIÇÃO & QUESTIONÁRIO \\
\hline $\begin{array}{l}\text { Conhecimento da Lei } \\
8.666 / 1993\end{array}$ & $\begin{array}{l}\text { Nível de familiaridade com e lei que rege } \\
\text { os processos de licitação e contratação de } \\
\text { forma geral. }\end{array}$ & $\begin{array}{l}\text { Qual o nível de conhecimento você possui sobre } \\
\text { a lei } 8.666 / 93 \text { que institui normas para licitação e } \\
\text { contratos da administração pública? }\end{array}$ \\
\hline $\begin{array}{l}\text { Conhecimento da Lei } \\
12.349 / 2010\end{array}$ & $\begin{array}{l}\text { Nível de familiaridade com a lei que } \\
\text { determina a adoção de critérios sustentáveis } \\
\text { para avaliação de fornecedores em } \\
\text { licitações e contratos. }\end{array}$ & $\begin{array}{l}\text { Qual o nível de conhecimento você possui } \\
\text { sobre a lei } 12.349 / 2010 \text { que regulamenta os } \\
\text { critérios ambientais em compras ou serviços nos } \\
\text { processos licitatórios? }\end{array}$ \\
\hline Aquisições Sustentáveis & $\begin{array}{l}\text { Nível de sustentabilidade percebida na } \\
\text { prática atual de processos de aquisição. }\end{array}$ & $\begin{array}{l}\text { Qual o nível de sustentabilidade ambiental } \\
\text { você considera que existe atualmente na } \\
\text { aquisição dos produtos/serviços licitados para } \\
\text { a manutenção da unidade gestora a qual você } \\
\text { está vinculado? }\end{array}$ \\
\hline Critérios Sustentáveis & $\begin{array}{l}\text { Adoção ou não de critérios de } \\
\text { sustentabilidade nos processos licitatórios. }\end{array}$ & $\begin{array}{l}\text { A Prefeitura a qual você está vinculado utiliza } \\
\text { critérios ambientais de sustentabilidade nos } \\
\text { processos licitatórios? Caso a resposta seja sim, } \\
\text { indique qual(is) Critério(s). }\end{array}$ \\
\hline $\begin{array}{l}\text { Benefícios } \\
\text { Organizacionais }\end{array}$ & $\begin{array}{l}\text { Contribuição percebida da prática de } \\
\text { aquisições sustentáveis para com os } \\
\text { objetivos da Administração. }\end{array}$ & $\begin{array}{l}\text { Qual o nível de contribuição você considera que } \\
\text { existe na adoção de critérios de sustentabilidade } \\
\text { ambiental nos processos licitatórios para o } \\
\text { cumprimento dos objetivos de sua unidade } \\
\text { gestora? }\end{array}$ \\
\hline Preparo dos Fornecedores & $\begin{array}{l}\text { Aptidão de fornecedores regionais para } \\
\text { participação e contratação em processos de } \\
\text { compras sustentáveis. }\end{array}$ & $\begin{array}{l}\text { Em que nível de preparo técnico você acredita } \\
\text { que se encontram os participantes/fornecedores } \\
\text { envolvidos nos processos licitatórios } \\
\text { sustentáveis em sua região? }\end{array}$ \\
\hline Benefícios Sociais & $\begin{array}{l}\text { Contribuição percebida da prática } \\
\text { de compras sustentáveis para o } \\
\text { desenvolvimento local por meio da geração } \\
\text { de empregos e na arrecadação de tributos. }\end{array}$ & $\begin{array}{l}\text { Em que nível você acredita que a licitação } \\
\text { sustentável pode contribuir para o } \\
\text { desenvolvimento local, com a geração de } \\
\text { emprego e efeito na arrecadação de tributos } \\
\text { federais, estaduais e municipais? }\end{array}$ \\
\hline Eficácia de Aquisições & $\begin{array}{l}\text { Nível de satisfação geral baseado na noção } \\
\text { de custo benefício dos produtos adquiridos, } \\
\text { considerando os atributos de eficiência, } \\
\text { durabilidade e economicidade. }\end{array}$ & $\begin{array}{l}\text { Em que nível você acredita que a licitação } \\
\text { sustentável pode contribuir para o } \\
\text { desenvolvimento local, com a geração de } \\
\text { emprego e efeito na arrecadação de tributos } \\
\text { federais, estaduais e municipais? }\end{array}$ \\
\hline Benefícios Institucionais & $\begin{array}{l}\text { Contribuição percebida da prática de } \\
\text { compras sustentáveis para a melhoria da } \\
\text { imagem do órgão e da aprovação da gestão } \\
\text { perante a sociedade local. }\end{array}$ & $\begin{array}{l}\text { Em que nível você acredita que a utilização } \\
\text { de produtos de origem sustentável torna bem- } \\
\text { vista a imagem de um gestor público perante a } \\
\text { sociedade? }\end{array}$ \\
\hline Benefícios Ambientais & $\begin{array}{l}\text { Contribuição percebida da prática de } \\
\text { compras sustentáveis para a redução de } \\
\text { impactos ambientais. }\end{array}$ & $\begin{array}{l}\text { Em que nível você acredita que a licitação } \\
\text { sustentável gera benefícios socioambientais e } \\
\text { reduz os impactos ambientais? }\end{array}$ \\
\hline
\end{tabular}

Fonte: Elaboração própria. 
TABELA 1 - Variação total explicada

\begin{tabular}{c|c|c|c|c|c|c}
\hline \multirow{2}{*}{ Componente } & \multicolumn{3}{|c|}{ Autovalores iniciais } & \multicolumn{3}{c}{ Somas rotativas de carregamentos } \\
& \multicolumn{3}{|c|}{ oo quadrado } \\
\cline { 2 - 7 } & Total & \% de variação & \% cumulativa & Total & \% de variação & \% cumulativa \\
\hline 1 & 3,277 & 32,772 & 32,772 & 3,114 & 31,140 & 31,140 \\
\hline 2 & 2,632 & 26,317 & 59,089 & 2,538 & 25,381 & 56,521 \\
\hline 3 & 1,756 & 17,558 & 76,647 & 2,013 & 20,126 & 76,647 \\
\hline 4 &, 748 & 7,481 & 84,128 & & & \\
\hline 5 &, 565 & 5,646 & 89,774 & & & \\
\hline 6 &, 352 & 3,519 & 93,293 & & & \\
\hline 7 &, 313 & 3,134 & 96,427 & & & \\
\hline 8 &, 164 & 1,644 & 98,072 & & & \\
\hline 9 &, 109 & 1,094 & 99,165 & & & \\
\hline 10 &, 083 &, 835 & 100,000 & & & \\
\hline
\end{tabular}

Fonte: Dados da Pesquisa.

TABELA 2 - Comunalidades

\begin{tabular}{|c|c|c|}
\hline Variável & Inicial & Extração \\
\hline Conhecimento da Lei 8.666/1993 & 1,000 & ,836 \\
\hline Conhecimento da Lei $12.349 / 2010$ & 1,000 & 876 \\
\hline Aquisições Sustentáveis & 1,000 & 897 \\
\hline Critérios Sustentáveis & 1,000 & ,659 \\
\hline Benefícios Organizacionais & 1,000 & ,832 \\
\hline Preparo dos Fornecedores & 1,000 & ,781 \\
\hline Benefícios Sociais & 1,000 & ,735 \\
\hline Eficácia de Aquisições & 1,000 &, 583 \\
\hline Conhecimento da Lei 8.666/1993 & 1,000 &, 715 \\
\hline Conhecimento da Lei $12.349 / 2010$ & 1,000 & ,751 \\
\hline
\end{tabular}

Fonte: Dados da Pesquisa.

\section{TABELA 3 - Matriz de Componentes Rotacionados}

\begin{tabular}{|c|c|c|c|}
\hline Variável & 1 & 2 & 3 \\
\hline Conhecimento da Lei 8.666/1993 & ,092 &, 245 & ,876 \\
\hline Conhecimento da Lei 12.349/2010 & 179 & ,158 & ,905 \\
\hline Aquisições Sustentáveis &, 916 &,- 077 &, 227 \\
\hline Critérios Sustentáveis &, 797 &, 122 &, 095 \\
\hline Benefícios Organizacionais & ,902 & ,111 & ,076 \\
\hline Preparo dos Fornecedores & ,849 &,- 150 &,- 194 \\
\hline Benefícios Sociais & ,019 & 853 &, 082 \\
\hline Eficácia de Aquisições & ,242 & ,492 &,- 532 \\
\hline Benefícios Institucionais &,- 071 & 834 & , 119 \\
\hline Benefícios Ambientais &, 016 & ,856 & 138 \\
\hline
\end{tabular}

Fonte: Dados da Pesquisa. 
formação desse componente sob a luz do framework construído por Brammer e Walker (20II), permite observar que, no caso em questão, existe uma fusão entre as influências exercidas pelos constructos de Percepção de Custo/benefício - por parte da unidade gestora de aquisições - e de Disposição/resistência do Fornecedor.

Nesse sentido, pressupõe-se a presença de uma cadeia de suprimentos na qual os atributos da sustentabilidade podem ou não estarem embutidas como consequência de estratégias competitivas, regulamentações Porter (1995) ou senão pelo reflexo local de ações políticas pautadas na visão conservacionista da cultura e geografia regional.

Portanto, esse primeiro componente, formado pelas quatro variáveis (Aquisições Sustentáveis, Critérios Sustentáveis, Benefícios Organizacionais e Preparo dos Fornecedores) é a Sustentabilidade Imanente.

A submissão das quatro variáveis escalonadas deste componente ao teste de confiabilidade de Cronbach apresentou um valor para alfa de 0,86I demonstrando a aptidão das questões aplicadas para a delimitação do constructo válido para análise.

Já o segundo componente, o Alinhamento Estratégico Sustentável, é constituído pelas variáveis Benefícios Sociais, Benefícios Institucionais e Benefícios Ambientais (cujos dados demonstraram confiabilidade mediante o Alfa de Cronbach de valor 0,836). De acordo com essas variáveis é possível vislumbrar o nível de informação da gestão de aquisições na administração municipal circunscrito ao escopo do modelo Triple Botton Line. Isso por que são abordadas, além do princípio da economicidade, as percepções dos aspec- tos socioambientais em associação com os processos de seleção de fornecedores e contratação.

Do mesmo modo, o aspecto institucional cujo reflexo pode ser definido pela qualidade da imagem que caracteriza um específico tipo de gestão, a depender do modo com o qual se lida com as aquisições sustentáveis, pode ser reforçado ou não. Em comparação ao modelo conceitual de Brammer e Walker (20I I), este segundo componente corresponde ao fator de influência denominado de Familiaridade com Políticas, para o qual é advogado o desenvolvimento de competências e habilidades a fim de suprir a necessidade de entendimento do conceito de Aquisições Sustentáveis e de suas políticas públicas relacionadas.

Nesse caso, em que pese a margem de subjetivismo e as possíveis inconsistências ao se definir o que é ou não sustentável, conforme aventado em Lélé (1995), a efetividade dos procedimentos de aquisições sustentáveis pressupõe um certo grau de homogeneidade em torno da noção assentada de sustentabilidade por parte dos agentes envolvidos, inclusive tornando possíveis o apoio e a aprovação da sociedade, bem como o engajamento da administração em adotar práticas sustentáveis ao reconhecer a importância dessa atitude como contribuição para o bem estar social e respeito aos limites do meio ambiente.

O terceiro e último componente, nomeado de Eficácia Legal, é delimitado pelas variáveis Conhecimento da Lei 8.666/1993, Conhecimento da Lei 12.349/20 10 e Eficácia de Aquisições, desvelando o requisito de uma expertise para execução, julgamento e tomada de decisões baseadas no aparato normativo, tendo 
em vista o seu teor complexo (porém não exaustivo) e burocrático para tratamento de aquisições de um modo geral.Também acaba por trazer consigo um condão limitador decorrente do princípio administrativo constitucional da legalidade, pelo qual os atos do gestor público, bem como seus respectivos efeitos, somente são validados se totalmente condicionados às suas previsões legais, impossibilitando maiores arbitrariedades semelhantes às empregadas na administração privada.

Encontrando-se agregada a esse aspecto a questão da eficácia das aquisições, o sinal negativo que acompanha o valor da carga fatorial $(-0,532)$ de sua variável correspondente, indica uma tendência dos agentes mais familiarizados com dispositivo legal em reconhecerem ex post as limitações observadas pela função custo/benefício das aquisições realizadas. Partindo da premissa de que o maior domínio da lei previne falhas oriundas de ações de planejamento e especificação do produto, tal situação pode ser explicada pela demasiada ênfase que o dispositivo legal adquiriu sobre a busca por produtos padronizados selecionados pelo critério de julgamento de menor preço, causando impressões ainda mais utópicas sobre a obtenção do melhor preço por meio julgamento dos custos diretos e indiretos, sociais, ambientais e econômicos defendida em (FREITAS, 20I I).

A disposição apresentada para as variáveis deste componente sugere uma fusão dos constructos de Familiaridade com as Regras e de Ineficiência Percebida propostos por Gelderman, Ghijsen e Brugman (2006) para explicar a não aplicação de diretrizes de seleção de fornecedores no âmbito da União Europeia. Trata-se, portanto, para o caso em questão, de um fator que sintetize a competência de adequar a necessidade real da unidade gestora ao campo restritivo legal primando pela eficácia da transação na medida do possível.

Uma vez identificados os três fatores responsáveis pela realização de aquisições sustentáveis no âmbito de uma administração pública municipal de acordo com os dados utilizados em um definido recorte temporal, seus valores estimados implicam na acepção de que as forças mercadológicas e o peso institucional, emanados do paradigma da sustentabilidade, atualmente exercem mais influência do que o marco legal, elaborado para que a administração pública assuma o sentido de incentivar o desenvolvimento e oferta e de produtos sustentáveis por meio de demand push, sobre a efetivação de transações e contratos mais sustentáveis, bem como na definição dos critérios de sustentabilidade dos produtos.

\section{CONSIDERAÇÕES FINAIS}

O presente estudo realizado buscou a identificação dos principais fatores responsáveis pela prática das contratações sustentáveis na administração pública em âmbito municipal, considerando a realidade dos municípios do Estado do Pará de acordo com a visão de seus agentes públicos. Tendo por base alguns construtos anteriormente estabelecidos pela literatura acerca do tema, foram identificados os fatores de Sustentabilidade Imanente, Alinhamento Estratégico Sustentável e de Eficácia Legal.

O conhecimento de tais fatores viabiliza a definição de políticas e planos de ações voltados para a o emprego de pressões e/ ou incentivos internos e externos à unidade administrativa, bem como a elaboração e promoção de programas de treinamento, capacitação e formação de agentes públicos 
dotados das competências necessárias para a efetivação de contratos sustentáveis, e a adequação dos dispositivos normativos à realidade concreta ao empregarem critérios objetivos capazes de aproximá-los da eficácia e efetividade aplicáveis pela administração pública. Diante dos resultados obtidos, a adaptação de um framework específico para a análise e tratamento dos processos de licitações e contratos sustentáveis praticados em uma realidade local foi lograda.

Contudo é importante salientar as possíveis limitações associadas a um estudo amparado em amostra não probabilística em termos de menores confiabilidade e probabilidade de que as ocorrências obtidas estejam próximas da média populacional, refletido seus atributos. Outrossim, os resultados aqui obtidos podem ser reforçados em caso de uma amostragem mais volumosa com um número de ocorrências bem superior aos quarenta utiliza- dos, ou senão mediante a sua triangulação com outros métodos de abordagem para o mesmo objeto como um estudo de caso ou observação mais aprofundada das práticas utilizadas em processos licitatórios em alguma unidade gestora contida do escopo deste estudo. Ademais, seria ainda mais enriquecedora, para fins de validação e comparação dos resultados aqui apresentados, a incorporação de casos associados a outros locais de estudos ou circunscritos nas outras esferas governamentais (Estados e União).

Finalmente, a identificação dos elementos estruturais subjacentes aos processos de contratações sustentáveis aqui empreendida enseja o avanço dos estudos no que se refere a definição de indicadores do nível de sustentabilidade atinente a uma determinada unidade gestora, bem como ao peso com que cada fator contribui para 0 seu balanço geral. 


\section{REFERÊNCIAS}

ALENCASTRO, M. A. C.; SILVA, E. V.; LOPES,A.M.D. Contratações sustentáveis na administração pública brasileira: a experiência do Poder Executivo Federal. Rev. Adm. Pública, Rio de Janeiro, v. 48, n. I, Jan./Feb. 2014.

BETIOL, L. S.; UEHARA, T. H. K.; LALOE, F; APPUGLIESE, G. A.; ADEODATO, S.; RAMOS, L.; NETO, M. P. M. Compra Sustentável: a força do consumo público e empresarial para uma economia verde e inclusiva. São Paulo: Programa Gestão Pública e Cidadania, 2012.

BRAMMER, S.; WALKER, H. Sustainable procurement in the public sector: An international comparative study. International Journal of Operations and Production Management, v.3I, n.4, p.452 476, 2011.

BRASIL. Decreto $n^{\circ} 7.546$, de 02 de agosto de 201I. Regulamenta o disposto nos $5^{\circ}$ a 12 do art. $3^{\circ}$ da Lei $n^{\circ} 8.666$, de 21 de junho de 1993, e institui a Comissão Interministerial de Compras Públicas.

Diário Oficial da União, Brasília, DF 03 ago. 201 I.

BRASIL. Decreto $n^{\circ} 7.756$, de 14 de Junho de 2012. Estabelece a aplicação de margem de preferência em licitações realizadas no âmbito da administração pública federal para aquisição de produtos de confecções, calçados e artefatos, para fins do disposto no art. $3^{\circ} \mathrm{da}$ Lei no 8.666 , de 21 de junho de 1993. Diário Oficial da União, Brasília, DF, I 5 jun. 2012.

BRASIL. Lei Complementar $n^{\circ}$ I47, de 7 de agosto de 2014. Altera a Lei Complementar no 123, de 14 de dezembro de 2006, e as Leis nos 5.889 , de 8 de junho de 1973 , II.I0I, de 9 de feverei- ro de $2005,9.099$, de 26 de setembro de 1995, II.598, de 3 de dezembro de 2007, 8.934, de 18 de novembro de 1994, 10.406, de 10 de janeiro de 2002, e 8.666, de 21 de junho de 1993; e dá outras providências. Diário Oficial da União, Brasília, DF, 07 ago. 2014.

BRASIL. Lei $\mathrm{n}^{\circ} \mathrm{II} .196$, de 21 de novembro de 2005. Institui o Regime Especial de Tributação para a Plataforma de Exportação de Serviços de Tecnologia da Informação - REPES, o Regime Especial de Aquisição de Bens de Capital para Empresas Exportadoras - RECAP e o Programa de Inclusão Digital; e dá outras providências. Diário Oficial da União, Brasília, DF, 22 nov. 2005.

BRASIL. Lei $n^{\circ} 12.349$ de 15 de dezembro de 2010. Altera as Leis 8.666, de 21 de junho de 1993 , 8.958, de 20 de dezembro de 1994, e 10.973, de 2 de dezembro de 2004; e revoga do $1^{\circ}$ do art. $2^{\circ}$ da Lei no II.273, de 6 de fevereiro de 2006. Diário Oficial da União, Brasília, DF, 16 dez. 2010.

BRASIL. Lei $n^{\circ} 8.666$, de 21 de junho de 1993. Regulamenta o art. 37, inciso XXI, da Constituição Federal, institui normas para licitações e contratos da Administração Pública e dá outras providências. Diário Oficial da União, Brasília, DF, 22 jun. 1993.

BRASIL. Ministério do Planejamento. Contratações Públicas Sustentáveis: o uso racional dos recursos públicos. Brasília, 20 I I. Disponível em: <http://cpsustentaveis. planejamento.gov.br/? $p=\mid 407>$. Acesso em: 30 jan. 2015.

BRASIL. Ministério do Planejamento. Informações gerenciais de contratações públicas sustentáveis. Brasília, 20|4. Disponível em: <http://www.comprasgovernamentais.gov.br/cidadao/informacoes-gerenciais/relatorios $>$. Acesso em: 30 jan. 2015.

FREITAS, J. Licitações e sustentabilidade: ponderação obrigatória dos custos e benefícios sociais, ambientais e econômicos. Interesse público, v.13, n.70, p. 15 - 35, nov./dez. $201 \mathrm{l}$.

GELDERMAN, C. J.; GHIJSEN, P.W.T.; BRUGMAN, M. J. Public procurement and EU tendering directives -explaining non-compliance. International Journal of Public Sector Management, v. 19, n. 7, p. 702-7|4, 2006.

GIL,A. C. Métodos e técnicas de pesquisa social. In: Métodos e técnicas de pesquisa social. São Paulo:Atlas, 2010.

HAIR, J. F. BLACK,W. C., BABIN, B. J., ANDERSON, R. E., \& TATHAM, R. L. Análise multivariada de dados. 6 ed. Porto Alegre: Bookman, 2009. 688 p.

INSTITUTO BRASILEIRO DE GEOGRAFIA E ESTATÍSTICA. Censo Demográfico 20I0. Brasília, DF. Disponível em: <http://www. censo20l0.ibge.gov.br>. Acesso em 20 fev. 2015.

LÉLÉ, S. M. Sustainable development: a critical review. World development, Great Britain, v. 19, n. 6, p. 607-621, 1995.

MCCRUDDEN, Christopher. Using public procurement to achieve social outcomes. Natural resources forum, v. 28 , n. 4 , p. 257 267, nov. 2004.

NASCIMENTO, J. O.; ZITTEI, M. V. M.; SOUZA, L. A. M.; LUGOBONI, L. F. Licitações Sustentáveis na Justiça do Trabalho. In: ENCONTRO INTERNACIONAL SOBRE GESTÃO E MEIO AMBIENTE, 16., 2014. São Paulo. Anais... São 
Paulo: Universidade de São Paulo, 2014.

PORTER, M. E.;VAN DER LINDE, C. SAMPIERI, ROBERTO H.; FERNÁNToward a new conception of the environment-competitiveness relationship. The journal of economic perspectives, v.9, n4, $\mathrm{p}$. 97-II8, 1995.

RENCHER, A. C. Methods of mul- tivariate analysis. 2. ed. Canadá: John Wiley \& Sons, 2002.

DEZ COLLADO, C.; BAPTISTA LUCIO, P. Metodología de la investigación. México: Editorial Mc Graw Hill, 2010.

UNITED NATIONS ENVIRONMENT PROGRAMME. The im- pacts of public sustainable procurement: eight illustrative case studies, Frace: UNEP, 2012.

UNITED NATIONS ENVIRONMENT PROGRAMME. Sustainable public procurement implementation guidelines: introducing UNEP's approach, France: UNEP, 20I2b. 